DOI: https://doi.org/10.24867/06HZ06Lazic

\title{
IZBOR OPTIMALNOG METODA KOMPOSTIRANJA U USLOVIMA NERAZVIJENIH SISTEMA UPRAVLJANJA OTPADOM
}

\section{DETERMINATION OF THE MOST OPTIMAL METHOD FOR COMPOSTING IN UNDERDEVELOPED WASTE MANAGEMENT}

\author{
Boško Lazić, Dejan Ubavin, Fakultet tehničkih nauka, Novi Sad
}

\section{Oblast - INŽENJERSTVO ZAŠTITE ŽIVOTNE SREDINE}

Kratak sadržaj - Radom je definisan i opisan čitav proces kompostiranja, navedeni su najznačajniji parametri koji utiču na odvijanje procesa. Takođe, opisane su tehnologije kompostiranja, način sprovođenja eskperimenta, analiza rezultata, kao $i$ preporuke za buduća istraživanja.

Ključne reči: Kompostiranje, Upravljanje otpadom

Abstract - The paper defines and describes the entire composting process, outlines the most important parameters that influence the process. It also describes composting technologies, how experiments are conducted, results analysis, and recommendations for future research.

Keywords: Composting, Waste management

\section{UVOD}

Biorazgradivi otpad (bio otpad) jeste otpad iz bašti, parkova, od hrane, kuhinjski otpad iz domaćinstva, restorana, ugostiteljstva i maloprodajnih objekata i sličan otpad iz proizvodnje prehrambenih proizvoda [1]. Visok udeo biorazgradivog otpada u mešanom komunalnom otpadu je odlika ekonomski nerazvijenih ili srednje razvijenih zemalja. Kada je reč o Republici Srbiji, biorazgradiv otpad predstavlja veoma značajan problem $u$ pogledu zaštite životne sredine jer se adekvatni tretmani ove vrste otpada izuzetno retko praktikuju ili ne praktikuju uopšte. Usled izostanka sistema koji podrazumeva razdvajanje otpada na mestu nastanka, najčešći tretman ili rešenje za ovu vrstu otpada je deponovanje, kako na smetlišta tako i na sanitarne deponije. Obzirom na Direktivu o deponijama Evropske unije i zabranu odlaganja biorazgradivog otpada na deponije, kompostiranje je prepoznato kao veoma značajno rešenje za tretman biorazgradivog otpada [2].

Procesi fermentacije i dekompozicije organskih materija dešavaju se u prirodi kontinualno i jednostavno bez ljudske pomoći. Odvijaju se na takav način da mnoge vrste crva i mikroorganizama poput bakterija i gljiva razgrađuju sav organski materijal na zemlji.

Dakle, kompostiranje je postupak koji se odvija uz pomoć

\section{NAPOMENA:}

Ovaj rad proistekao je iz master rada čiji mentor je bio dr Dejan Ubavin, van. prof. čoveka, u cilju razgradnje organske materije, u prisustvu kiseonika i relativno brzo, da bi se kontaminirani otpad efikasno preveo $\mathrm{u}$ organsko đubrivo bez biljnih bolesti $\mathrm{i}$ semena korova [3].

Kompost, kao takav, poboljšava stanje tla, smanjuje eroziju i pomaže u suzbijanju biljnih bolesti [4].

\section{PROCES KOMPOSTIRANJA}

Kompostiranje predstavlja prirodni proces biološko-hemijske razgradnje organske materije uz pomoć mikroorganizama u kontrolisanim uslovima. Bliže posmatrano, predstavlja biološki tretman tokom kojeg aerobni mezofilni i termofilni mikroorganizmi transformišu organsku materiju u vodu $\left(\mathrm{H}_{2} \mathrm{O}\right)$, ugljen-dioskid $\left(\mathrm{CO}_{2}\right)$, amonijak $\left(\mathrm{NH}_{3}\right)$ i kompost [5].

\subsection{Faktori koji utiču na proces kompostiranja}

Pošto je kompostiranje biološki proces koji vrše mikroorganizmi, treba uzeti u obzir parametre koji utiču na njihov rast i razmnožavanje. Svi parametri koji su značajni za odvijanje samog procesa moraju biti pod stalnim nadzorom kako bi se uvek nalazili u optimalnom opsegu [6].

Efikasnost procesa kompostiranja zavisi od velikog broja faktora, a najvažniji od njih su: odnos ugljenika i azota, veličina čestica, temperatura, koncentracija kiseonika, nivo vlažnosti i $\mathrm{pH}$ vrednost [7].

\subsection{Sakupljanje i priprema sirovine}

Većina ekonomskih pokazatelja, kao i pokazatelja efikasnosti metode kompostiranja veoma zavisi od izabranog metoda sakupljanja kompostne sirovine. Sakupljanje se može organizovati tako da se se odvojeno ili zajedno sakupljaju baštenski otpad i biorazgradivi otpad iz komunalnog otpada, takozvani kuhinjski otpad. Sakupljanje se može vršiti po domaćinstvima prilikom čega se sprovodi direktno sakupljanje materijala iz domaćinstava, ili na deponijama gde proizvođači ove vrste otpada ostavljaju te materijale na predviđenom mestu.

Pre samog formiranja kompostnih gomila, u kojima će se odvijati proces razgradnje organske materije, potrebno je pripremiti sirovinu, na način koji će obezbediti optimalnu veličinu frakcija sirovine, kao i zastupljenost različitih materijala sa različitim osobinama (sadržaj vlage, odnos ugljenika i azota, kiselost/baznost).

Optimalna veličina frakcija postiže se usitnjavanjem sirovine koja je predviđena za kompostiranje. Glavni 
razlog zbog kojeg se vrši usitnjavanje jeste povećanje površine u odnosu na zapreminu sirovinskog materijala. $\mathrm{Na}$ ovaj način se znatno ubrzava razgradnja kompostnih materijala, što je posledica povećane površine na koju mogu da deluju različite vrste mikroorganizama.

\subsection{Tehnologija kompostiranja}

Proces kompostiranja može se izvesti u jednostavnim okruženjima (podložno spoljašnjim uticajima, kao i u znatno složenijim sistemima, odnosno strogo kontrolisanim uslovima. Metode kompostiranja, koje se najčešće koriste (pobrojane po kompleksnosti) su:
1. pasivne gomile,
2. gomile u vrsti,
3. statične gomile sa prinudnom aeracijom i
4. zatvoreni sistemi [4].

\subsection{Faza sušenja}

Po završetku procesa kompostiranja potrebno je sprovesti poslednju fazu, odnosno fazu sušenja. Sušenje treba započeti kada materijali unutar kompostne gomile postanu dovoljno stabilni.

Faza sušenja služi za stabilizaciju komposta, dok se preostali slobodni nutrijenti razgrađuju pod uticajem preostalih mikroorganizama. Tokom trajanja ove faze mikrobiološka aktivnost opada kako se troše nutrijenti, kao i tokom čitavog procesa kompostiranja.

\subsection{IZVOĐENJE EKSPERIMENTA}

Metod kojim je sproveden eksperiment kompostiranja jeste metod gomila u vrsti. Izabran je pre svega zbog jednostavnosti načina obezbeđivanja optimalnog nivoa kiseonika tokom procesa kompostiranja. Glavni razlog izbora ovog metoda jeste interesovanje za ispitivanjem najjednostavnijeg sistema koji bi mogao biti primenjiv u najvećem broju slučajeva.

Eksperiment je sproveden iz dva dela, i to u različitim vremenskim intervalima, ali sa približno sličnim sirovinama. Oba dela eksperimenta, na samom početku svakih od njih, pratilo je prikupljanje neophodnih sirovina za formiranje kompostne gomile. Prikupljene su sirovine koje su sačinjene od „braon“ (bogatih ugljenikom) i „zelenih“ (bogatih azotom) delova.

Kada je reč o drugom delu eksperimenta, „braon“ deo takođe činilo je sakupljeno otpadno granje, lišće i slama, dok je ,zeleni“ deo činio otpadni mulj organskog porekla, koji je nastao kao produkt u procesu prečišćavanja otpadnih voda iz postrojenja za prečišćavanje otpadnih voda u Šapcu.

Za prvi deo eksperimenta gomilu koja je formirana sačinjavalo je 12 tona materijala, i to: 6 tona ,zelene“ (trava) i 6 tona „braon“ (granje, lišće i slama) frakcije. Visina formirane gomile iznosila je oko 0,75 metara, te se na taj način omogućila pravilna izolacija kompostnog materijala, te se na taj način sprečilo oslobađanje viška toplote, što je u slučaju prvog dela eksperimenta bilo od izuzetne važnosti jer se odvijao u uslovima srednje niskih temperatura. Širina kompostne gomile iznosila je oko 1,75 metara, a ona najviše zavisi od mehanizacije koja se koristi za prevrtanje i najčešće je jednaka visini gomile puta dva. Dužina gomile ima mali uticaj na kompostni proces, a nakon formiranja gomile za prvi deo eksperimenta iznosila je oko 16 metara.

Drugi deo eksperimenta, nakon prikupljanja i pripreme sirovina, otpočeo je formiranjem kompostne gomile koju je sačinjavalo 6 tona ,zelenog“ (otpadni mulj) i 6 tona „braon“ dela (otpadno granje, lišće i slama). Visina formirane gomile iznosila je oko 0,70 metara, širina 1,50 metara, a dužina oko 13 metara.

Obezbeđivanje optimalnog nivoa vlažnosti tokom eksperimenta vršeno je na takav način da su se jednom nedeljno uzimali reprezentativni uzorci iz gomila, a zatim laboratorijski određivala vlažnost unutar iste i proračunavala potrebna količina vode za uspostavljanje optimalnih uslova.

U cilju obezbeđivanja otpimalnog nivoa kiseonika unutar kompostne gomile, pristupalo se prevrtanju uz pomoć traktora i priključne mašine, tačnije prevrtača. Prevrtanjem je, osim nivoa kiseonika, vršeno regulisanje temperatura unutar kompostne gomile. Parametri koji su praćeni tokom čitavog eksperimenta bili su temperatura i vlažnost, a pored njih periodično su proveravane $\mathrm{pH}$ vrednost kao i koncentracija kiseonika.

\subsection{REZULTATI I NJIHOVA ANALIZA}

Kao što je $\mathrm{u}$ prethodnom delu rada napomenuto, temperatura je ključan parametar koji se koristi za praćenje procesa kompostiranja jer direktno ukazuje na mikrobiološku aktivnost.

U prvom delu eksperimenta nivoi temperatura su mereni periodično u tromesečnom vremenskom intervalu. Zbog prevelikog obima podataka na Grafiku 1. dat je prikaz temperatura u preseku A1, za merenje inteziteta dva do tri puta u toku nedelje, tokom čitavog tromesečnog praćenja. Rezultatima su obuhvaćena merenja za sve tri zone ovog preseka, za tačno dvadeset merenja sprovedenih tokom odvijanja procesa.

\section{Grafik 1. Raspored temperature u jednom od mernih preseka}

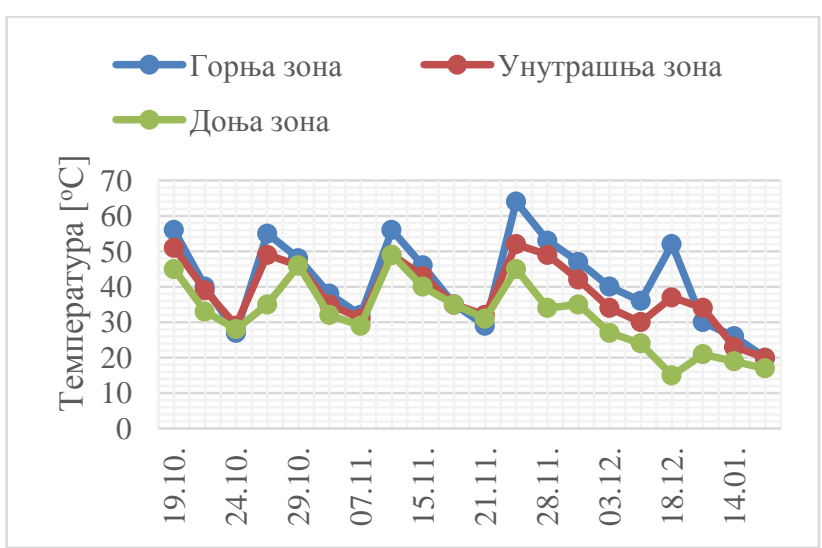

Kao što se sa grafika može zaključiti, intenzivni deo procesa kompostiranja trajao je tri meseca, te je nakon toga kompostna sirovina ostavljena da se suši. Takođe, sa prethodnih grafika, može se primetiti da se ekpseriment odvijao u uslovima srednje niskih temperatura, ali i pored toga prikaz temperatura ukazuje na izuzetno intenzivnu aktivnost mikroorganizama odnosno veoma efikasnu razgradnju organske materije. Na Slici 1 . može se videti 
izled kompostne gomile po završetku intenzivnog dela kompostiranja.

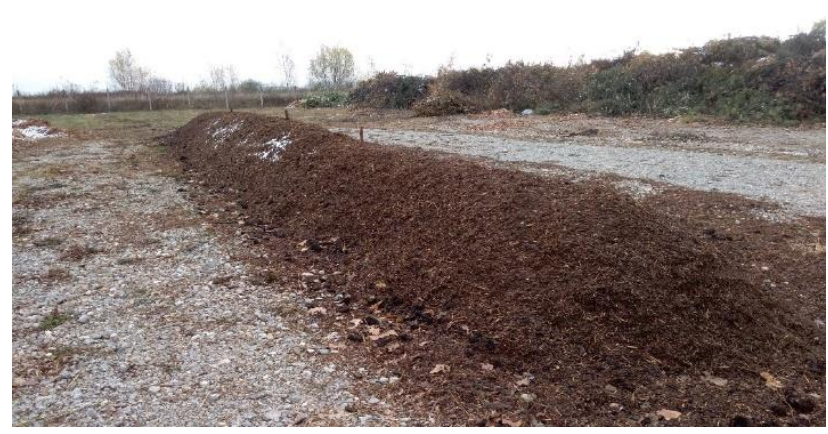

Slika 1. Izgled kompostne gomile po završetku prvog dela eksperimenta

Kada je reč o drugom delu eksperimenta, nivoi temperatura su mereni periodično u dvomesečnom vremenskom intervalu. Takođe, zbog prevelikog obima podataka na Grafiku 2. može se videti raspored temperatura u preseku A1, tokom čega je intezitet merenja takođe iznosio dva do tri puta nedeljno. Grafikom je dat prikaz dvadeset merenja koja su sprovedena tokom čitavog dvomesečnog praćenja procesa, a čime su obuhvaćena merenja za sve tri zone ovog preseka.

Grafik 2. Raspored temperature u jednom od mernih preseka (drugi deo eksperimenta)

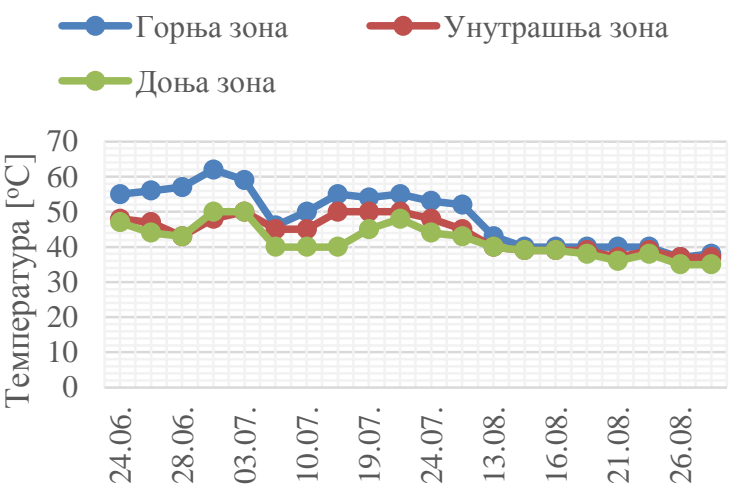

Analizom rezultata prikazanih na prethodnom grafiku, zaključuje se da je intenzivni deo procesa kompostiranja trajao dva meseca, nakon čega je kompostni materijal ostavljen da se suši, odnosno zri. Visoke temperature tokom odvijanja ovog dela eksperimenta ukazuju na veoma intenzivnu biološku razgradnju, te na uspešno završenu prvu fazu ovog dela eksperimenta. Na Slici 2. može se videti izgled kompostne gomile, drugog dela eksperimenta, po završetku intenzivne faze kompostiranja.

Iako je kompostiranje u oba dela eksperimenta vršeno istom metodom, može se primetiti značajna razlika $u$ vremenskom intervalu $u$ kojem su delovi završeni, odnosno u za koje vreme je proces kompostranja u oba slučaja završen. Kao što je u prethodno navedeno, prvi deo eksperimenta trajao je 3 meseca, nakon čega je kompost ostavljen da zri, dok je u drugom delu eksperimenta trajao 2 meseca, što predstavlja značajnu razliku.

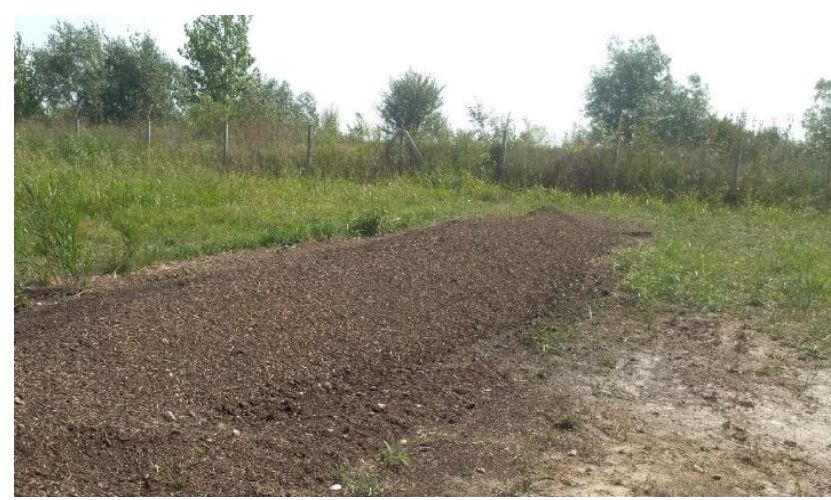

Slika 2. Izgled kompostne gomile po završetku drugog dela eksperimenta

Osim razlike u vremenu odvijanja procesa, značajno je pomenuti i razlike u samom upravljanju procesom. Naime, kada je reč o prvom delu eksperimenta, prevrtanje kompostne gomile je bilo potrebno sprovoditi svakih 7 do 10 dana, dok se za drugi deo isti postupak morao sprovoditi svakih 7 dana. Potreba za češćim prevrtanjem može se protumačiti kao brža potrošnja kiseonika unutar kompostne gomile, u slučaju drugog dela eksperimenta, što je na kraju, uz obezbeđivanje svih optimalnih uslova pravovremeno, dovelo do znatno kraćeg vremenskog intervala odvijanja pomenutog procesa.

Kada je reč o obezbeđivanju optimalnog nivoa vlažnosti unutar gomila, gomilu u prvom delu eksperimenta bilo je potrebno zalivati (dodavati vodu) jednom u 7 dana, dok je za drugi deo karakteristično to da zalivanje nije bilo potrebno. Iako se, u drugom delu eksperimenta, radi o obezvodnjenom mulju koji sadrži više od $70 \%$ vlage u sebi, kod takve vrste otpadnog mulja, nastalog iz procesa prečišćavanja otpadnih voda, radi se o takozvanoj vezanoj vlagi koja je teško uklonjiva. Drugim delom eksperimenta pokazano je da je takva vrsta materijala veoma pogodna za kompostiranje, ali treba imati u vidu da se eksperiment sa takvim materijalima mora izvoditi uz sve mere predostrožnosti, zaštitne opreme i uz jasno postavljanje cilja u odnosu na kvalitet finalnog proizvoda jer se u takvim muljevima nalazi značajna količina patogenih mikroorganizama, teških metala, farmaceutika i drugih supstanci koje su i mogu biti štetne po ljudsko zdravlje [8].

\section{ZAKLJUČAK}

Uticaj kompostiranja na životnu sredinu može biti zanemarljivo mali ukoliko se čitavim procesom upravlja na adekvatan način. Sa druge strane, ukoliko se procesom upravlja na neadekvatan način može doći do emitovanja raznih supstanci u sve medijume životne sredine (vazduh, vodu i zemljište). Zbog sve prethodno navedenog, kompostiranje je prepoznato kao veoma jednostavno, ali efikasno rešenje za zbrinjavanje kako velikih tako i malih količina biorazgradivog otpada.

Kompostiranje pruža čitav niz tehnologija, od veoma jednostavnih i ekonomski pristupačnih velikom broju ljudi, preduzeća, gradova i država, sve do izuzetno skupih sistema, koji podrazumevaju upotrebu visoke tehnologije za tretman specifičnih vrsta biorazgradivog otpada. 
Ovim radom je pokazano da i prva kategorija prethodno pomenutih tehnologija, jeste jedna od onih koje mogu biti najzastupljenije u najvećem broju slučajeva, odnosno može biti izuzetno efikasna pri zbrinjavanju otpada organskog porekla.

Ukoliko bi se šire uvela primena ove tehnologije tretmana otpada, ciljevi ispunjenosti zahteva zakonske regulative koji se odnose na smanjenje odlaganja organskog otpada na deponije bili bi znatno lakše ispunjeni. Sa jedne strane to se odrazilo na povećanje troškova upravljanja otpadnom, dok bi sa druge strane i rezultovalo smanjenje troškova zbog smanjenih količina otpada koji završava na deponijama.

Šira primena ove tehnologije takođe bi zančajno smanjila negativan uticaj na životnu sredinu i zdravlje ljudi, do kojeg dolazi usled nepostojanja adekvatnog sistema za tretman biorazgradivog otpada.

U slučaju uspostavljanja tržišta, ovom tehnologijom obezbedio bi se proizvod koji svoju primenu može pronaći u poljoprivredi, hortikulturi, nasipanju zemljišta i sličnim aktivnostima.

Osnovni preduslovi za uspešno odvijanje procesa kompostiranja su:

1. Obezbeđivanje podataka o raspoloživim sirovinama i njihovom kvalitetu,

2. izbor adekvatne metode u realnim uslovima,

3. priprema sirovina,

4. formiranje gomila adekvatne proporcije ulaznih sirovina,

5. kontinualno praćenje i učestvovanje $u$ podsticanju odvijanja procesa,

6. obezbeđivanje adekvatnog vremenskog intervala za fazu sušenja (zrenja),

7. prosejavanje zrelog komposta,

8. distribuciju kompostnog materijala do krajnjih korisnika.

Preporuke za naredna istraživanja date su u nastavku:

1. Sprovođenje procesa kompostiranja vrstama i količinama sirovina istoventnim iz ovog eksperimenta, nekom od preostalih metoda, te dalje utvrđivanje efikasnosti procesa kompostiranja, odnosno brzine i vremenskog perioda u kome se proces odigrao,

2. sprovođenje procesa kompostiranja gomilama u vrsti, ali korišćenjem sirovine kao što je biorazgradiv otpad iz mešanog komunalnog otpada, odnosno otpad od hrane, zajedno sa biljnim otpadom,

3. isptitati uticaje na životnu sredinu svih metoda za kompostiranje, kao i uticaj na čoveka,

4. sprovesti istraživanje na temu zaštite na radu prilikom čitavog procesa kompostiranja, od prikupljanja sirovine do pakovanja finalnog proizvoda,

5. ispitati ekonomske aspekte svih metoda kompostiranja u cilju pronalaženja ekonomski najpovoljnije, a prihvatljivo efikasne metode.

\section{LITERATURA}

[1] Zakon o upravljanju otpadom (Službeni glasnik Rebublike Srbije, broj 36/2009 i 88/2010)

[2] Goran Vujić, Izazovi transfera novih tehnologija u zemlje u razvoju u oblasti upravljanja otpadom, Novi Sad, Fakultet tehničkih nauka, 2017.

[3] Roula Fares, Elie Fares \& Federico De Nardo, Composting from A to Z, 2011.

[4] US Environmental Protecion Agency, Composting of yard trimmings and municipal solid waste, 1994.

[5] D. Kučić \& F. Briški, Emision of Gases During Composting of Solid Waste, 2017.

[6] Pilar Roman, Maria M. Martinez \& Alberto Pantoja, Farmers Compost Handbook, Experiences in Latin America, Food and Agriculture Organization of the UN, Santiago, 2015.

[7] R. Oveido-Ocana, L. F. Marmolejo-Rebellon, P. Tores-lozata \& others, Effect of adding bulking materials over the composting proces of municipal solid biowastes, 2015.

[8] P. Kosobucki, A.Chmarzynski \& B. Buszevski, Sewage Sludge Composting, 2000.

\section{Kratka biografija:}

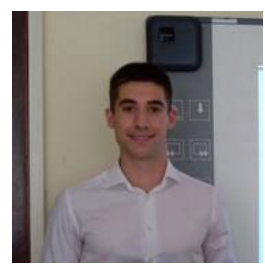

Boško Lazić rođen je u Šapcu 1994. god. Master rad na Fakultetu tehničkih nauka iz oblasti Upravljanje otpadom Izbor optimalnog metoda kompostiranja u uslovima nerazvijenih sistema upravljanja otpadom odbranio je 2019.god.

kontakt: boskolazic@uns.ac.rs

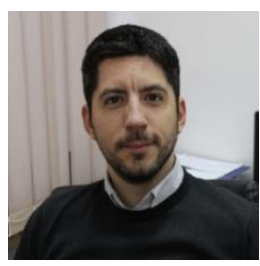

Dejan Ubavin rođen je u Novom Sadu 1980. godine. Doktorirao je 2012. godine na Fakultetu tehničkih nauka, u zvanju vanredni profesor je od 2017. godine, direktor je departmana za inženjerstvo zaštite životne sredine i zaštite na radu od 2015. godine. 